\title{
Heparan Sulfate Regrowth Profiles Under Laminar Shear Flow Following Enzymatic Degradation
}

\author{
Kristina M. Giantsos-Adams, ${ }^{1,6}$ Andrew Jia-An Koo, ${ }^{2}$ Sukhyun Song, ${ }^{3}$ Jiro Sakai, ${ }^{1}$ \\ Jagadish Sankaran, ${ }^{4}$ Jennifer H. Shin, ${ }^{3}$ Guillermo Garcia-Cardena, ${ }^{5}$ and C. Forbes Dewey Jr. ${ }^{1,2}$ \\ ${ }^{1}$ Department of Mechanical Engineering, Massachusetts Institute of Technology, 77 Massachusetts Avenue, Rm. 3-254, \\ Cambridge, MA 02139, USA; ${ }^{2}$ Department of Biological Engineering, Massachusetts Institute of Technology, 77 Massachusetts \\ Avenue, Cambridge, MA, USA; ${ }^{3}$ Department of Bioengineering, Korean Advanced Institute for Science and Technology, 291 \\ Daehak-ro (373-1 Guseong-dong), Yuseong-gu, Daejeon, Korea; ${ }^{4}$ National University of Singapore, E4-04-10, 4 Engineering \\ Drive 3, Singapore, Singapore; ${ }^{5}$ Department of Pathology, Brigham and Women's Hospital, Harvard Medical School, 77 \\ Avenue Louis Pasteur, Boston, MA, USA; and ${ }^{6}$ Department of Mechanical Engineering, Massachusetts Institute of Technology, \\ 77 Massachusetts Avenue, Rm. 3-254, Cambridge, MA 02139, USA
}

(Received 4 November 2012; accepted 7 February 2013; published online 20 February 2013)

Associate Editor Frank C.-P. Yin oversaw the review of this article.

\begin{abstract}
The local hemodynamic shear stress waveforms present in an artery dictate the endothelial cell phenotype. The observed decrease of the apical glycocalyx layer on the endothelium in atheroprone regions of the circulation suggests that the glycocalyx may have a central role in determining atherosclerotic plaque formation. However, the kinetics for the cells' ability to adapt its glycocalyx to the environment have not been quantitatively resolved. Here we report that the heparan sulfate component of the glycocalyx of HUVECs increases by 1.4-fold following the onset of high shear stress, compared to static cultured cells, with a time constant of $19 \mathrm{~h}$. Cell morphology experiments show that $12 \mathrm{~h}$ are required for the cells to elongate, but only after $36 \mathrm{~h}$ have the cells reached maximal alignment to the flow vector. Our findings demonstrate that following enzymatic degradation, heparan sulfate is restored to the cell surface within $12 \mathrm{~h}$ under flow whereas the time required is $20 \mathrm{~h}$ under static conditions. We also propose a model describing the contribution of endocytosis and exocytosis to apical heparan sulfate expression. The change in HS regrowth kinetics from static to high-shear EC phenotype implies a differential in the rate of endocytic and exocytic membrane turnover.
\end{abstract}

Keywords-Endothelial glycocalyx, Shear stress, Heparan sulfate, Heparinase, Glycocalyx injury, Transport model.

\section{INTRODUCTION}

The endothelial glycocalyx layer on the apical surface of vascular endothelial cells is a complex arrangement of

Address correspondence to Kristina M. Giantsos-Adams, Department of Mechanical Engineering, Massachusetts Institute of Technology, 77 Massachusetts Avenue, Rm. 3-254, Cambridge, MA 02139, USA. Electronic mail: kmadams@mit.edu, cfdewey@ mit.edu proteoglycans, glycosaminoglycans (GAG), and glycolipids that regulate the ability of the endothelium to sense and respond to extracellular physical and chemical cues. The glycocalyx has been implicated in the regulation of athero-resistant gene expression, ${ }^{10,29}$ alignment of cells to an imposed flow vector, ${ }^{44}$ modulation of inflammatory pathways, ${ }^{24}$ and modulation of the diffusion of micro- and macromolecules between the vessel lumen and the cell surface. ${ }^{17}$ Structural changes in the glycocalyx are thought to be the initial proatherogenic step that leads to increased affinity of lipoproteins for vascular subendothelium (reviewed in Ballinger et al. ${ }^{6}$ ). Moreover, atherosclerotic lesions exhibit heparan sulfate chains with significant oxidative damage, thereby decreasing their ability to bind growth factors. ${ }^{20}$

Heparan sulfate (HS) is the dominant constituent of the glycocalyx. It is a linear sulfated polysaccharide, formed of 40-300 sugar residues, approximately 20$150 \mathrm{~nm}$ in length, and is anchored to the apical core proteins, syndecans and glypicans. HS plays an active and necessary role in the cellular response to environmental stimuli. ${ }^{2,11}$ It has been implicated in the shear-stress-induced expression of von Willebrand factor and VE-cadherin, ${ }^{26}$ along with the vasoregulatory proteins cyclooxygenase-2 (COX-2) and nitric oxide synthase (eNOS) ${ }^{26,28}$ Heparan sulfate also serves as a reservoir for extracellular proteins, such as FGF2, vascular endothelial growth factor, and lipoprotein lipase (reviewed by Sarrazin et al. ${ }^{36}$ ), and can modulate the activity of the protein through receptorligand interactions. ${ }^{35}$

In vivo, $\mathrm{HS}$ is cleaved by heparanase, an endoglycosidase capable of selectively cleaving heparan sulfate 
from the glycocalyx layer while leaving the core protein intact. ${ }^{9}$ Heparanase is found in high concentrations in platelets, macrophages, ${ }^{41}$ and invading tumor cells ${ }^{42}$ and it has been suggested that normal and malignant blood-borne cells may utilize this enzymatic machinery to escape the vasculature. ${ }^{41}$ High levels of glucose and reactive oxygen species, characteristic of diabetes and inflammation, respectively, increase endogenous heparanase production, leading to increased arterial heparan sulfate degradation. ${ }^{32}$ Under shear stress, the enzymatic removal of heparan sulfate from endothelial cells results in their loss of alignment along the flow vector ${ }^{44}$ and attenuates the production of the vasodilator nitric oxide. ${ }^{15}$ Along with matrix metalloproteinase activity, enzymatic degradation of the glycocalyx also provides benign and malignant circulating cells with access to the subendothelial basement membrane. ${ }^{25}$

The glycocalyx provides a force-sensitive region between the flowing blood vessels and the arterial wall whose thickness depends upon the local shear forces imposed by the fluid flowing at its outer surface. ${ }^{33}$ High shear stress increases the rate of glycocalyx biosynthesis on porcine aortic endothelium compared to cells experiencing no shear. ${ }^{3}$ The increase in glycocalyx under high shear stress has been noted elsewhere, ${ }^{7,18,39}$ but its growth kinetics under shear stress and following heparanase treatment have not been explored until now. Here we report the time course for the regrowth of heparan sulfate following heparinase treatment, and explore the potential influence of endocytosis and exocytosis on the rates of recovery. These findings have application to atherosclerosis, ${ }^{32}$ diabetes,${ }^{14}$ and cancer disease models, ${ }^{5,14,37}$ as it is becoming increasingly clear that heparanase expression has wide-reaching and deleterious effects in multiple regions of the vasculature.

\section{MATERIALS AND METHODS}

\section{Cell Culture and Reagents}

Primary human umbilical vein endothelial cells (HUVEC) were cultured in Medium 199 buffered with $25 \mathrm{mM}$ HEPES and supplemented with $2 \mathrm{mM}$ L-glutamine, $20 \%$ fetal bovine serum (FBS, Gibco), and 1\% penicillin-streptomycin (Gibco). On the day of use, $50 \mu \mathrm{g} / \mathrm{mL}$ endothelial growth factor (ECGS, Invitrogen) and $100 \mu \mathrm{g} / \mathrm{mL}$ heparin were added. Cells were used passage 1-3 and were kept in a humidified incubator at $37{ }^{\circ} \mathrm{C}$ supplied with $5 \% \mathrm{CO}_{2}$. All reagents were purchased from Sigma unless otherwise specified. Heparinase III (cat. \#50-012) was obtained from Ibex (Montreal, Quebec, Canada) and anti-heparan sulfate antibody 10E4 was obtained from US Biological
(Swampscott, MA). DyLight 549 IgM secondary antibody was purchased from Jackson Immunoresearch (West Grove, PA). The cell preservation and imaging medium, ProLong Gold, and the nuclear dye, 4',6diamidino-2-phenylindole dihydrochloride (DAPI), were obtained from Invitrogen (Carlsbad, CA).

\section{Heparan Sulfate Removal and Immunostaining}

For heparan sulfate removal, the monolayer was exposed to heparinase III (HpaseIII, $15 \mathrm{mU} / \mathrm{mL}$ ) for $10 \mathrm{~min}$ at $37^{\circ} \mathrm{C}$, then rinsed thoroughly with PBS, covered with cell culture medium, and placed in the incubator for a predetermined time interval. At the end of the incubation, cells were fixed with $4 \%$ paraformaldehyde for 15 min then blocked with $5 \%$ donkey serum for $30 \mathrm{~min}$. Cells were then treated with antiheparan sulfate antibody (1:100 dilution) for $30 \mathrm{~min}$ at $20{ }^{\circ} \mathrm{C}$, rinsed thoroughly, and treated with a fluorescently labeled secondary antibody (1:500 dilution, DyLight 549) for $30 \mathrm{~min}$ at $20^{\circ} \mathrm{C}$. Cells were then incubated with DAPI ( $2 \mu \mathrm{M}$ for $5 \mathrm{~min})$ and rinsed thoroughly. Cells were quickly dried by aspiration and covered with ProLong gold antifade mounting medium. The mounting agent was allowed to cure for $24 \mathrm{~h}$ protected from light before imaging.

\section{Shear Stress Apparatus}

HUVEC were seeded at $2.5 \times 10^{5}$ cells $/ \mathrm{cm}^{2}$ in Ibidi $\mu$-slide VI flow channels (Ibidi USA, Verona, WI) coated with $0.1 \%$ gelatin and allowed to incubate at $37{ }^{\circ} \mathrm{C}$ with $5 \% \mathrm{CO}_{2}$ for $24 \mathrm{~h}$ to facilitate attachment and growth to confluent monolayers. Each Ibidi $\mu$-slide had six independent flow channels containing independent HUVEC monolayers. For the duration of shear experiments, the Ibidi chambers were housed in a miniature incubator (Bioscience Tools, San Diego, $\mathrm{CA}$ ) and temperature was maintained at $37^{\circ} \mathrm{C}$. Each of the six individual channels was attached via Luer connectors to a sterile silicone tube that was fed through an Ismatec 32 channel roller pump (Ismatec, Oak Harbor, WA). Medium at $37^{\circ} \mathrm{C}$ was flowed over cell monolayers at a rate of $8.5 \mathrm{~mL} / \mathrm{min}$, generating a fluid shear stress on the cell surface of $15 \mathrm{dyn} / \mathrm{cm}^{2}$.

\section{Fluorescence Microscopy}

Images were acquired using a cooled CCD camera and MaxIm acquisition software (Apogee Instruments) housed on a Nikon Eclipse TE2000U inverted microscope with $20 \times 0.50 \mathrm{NA}$ PlanFluor objective. Each image represents a $742 \times 500 \mu \mathrm{m}$ field of approximately 300 confluent cells. No fewer than three images were acquired from each channel. Acquired images were stored as $16 \mathrm{bit}$ 
linear files and processed with ImageJ software. The background fluorescence was defined as the fluorescence observed with cells stained with secondary antibody and DAPI only. Subtraction of the background yielded the final mean intensity values for cell surface heparan sulfate. The reported standard deviation represents the spread of the mean intensity of multiple images, which were acquired over multiple monolayers of the same treatment group. For each experiment involving heparinase, a monolayer of HUVEC was stained for HS. At least three images were acquired and the mean intensity of this group served as the value to which intensity values from all other experimental groups were normalized.

\section{Cell Shape Evaluation}

Phase contrast images obtained at $20 \times$ magnification during heparan sulfate regrowth and immunostaining step were evaluated using ImageJ. Fifteen cells randomly chosen from each image were traced to obtain cell area (a) and perimeter $(p)$, which were used to calculate the circularity index $(S)$, based on the following formula:

$$
S=\frac{2 \sqrt{\pi a}}{p}
$$

The alignment of the cells along the flow axis was calculated by measuring the angle $\varnothing$ that is created by the intersection of the line connecting the two farthest points at the cell periphery with the flow vector.

\section{Statistical Analysis}

All results are presented as mean \pm standard deviation and statistical significance is set to $p<0.05$. Statistics for normally distributed data, such as from quantitative fluorescence microscopic images, was determined by ANOVA and a Student-Newman-Keuls post hoc test if more than 2 groups were being assessed. For circularity index and alignment angle data that are not normally distributed, the Wilcoxon test for unpaired data was used to compare two groups and Kruskal-Wallis test was used to compare data from more than 2 groups. All statistical analyses were performed using Kaleidagraph software (Synergy Software, Reading, PA). Numbers of data points in a set and other information pertinent to a particular data set are given in the figure captions.

\section{RESULTS}

\section{Heparan Sulfate Levels are Constant Over Time in Static Cells}

Heparan sulfate levels did not change significantly for any time between 24 and $84 \mathrm{~h}$ after plating (Fig. 1).
The cells were seeded at $2.5 \times 10^{5}$ cells $/ \mathrm{cm}^{2}$, which is a sufficiently high concentration to produce attachment to the substrate within $24 \mathrm{~h}$ that does not require further proliferation to achieve confluence. The mean fluorescence intensity values range from 14.9 to 19.3 and no statistical differences were observed between any time points $(\alpha=0.05)$. The lack of a trend between or significant difference among any of the groups signifies that heparan sulfate content on HUVEC is stable over time and that the acquisition method is valid.

\section{Heparan Sulfate Levels Increase Under Shear}

Application of $15 \mathrm{dyn} / \mathrm{cm}^{2}$ laminar shear flow to HUVEC monolayers results in a $40 \%$ increase in HS levels as compared to statically cultured HUVEC. The time course for heparan sulfate growth is shown in Fig. 2. HS levels begin to rise as cells are exposed to shear for $12 \mathrm{~h}$ and continue to increase toward an asymptote at long times ( $>48 \mathrm{~h})$.

To obtain a quantitative measure of the increasing heparan sulfate levels, the data were fitted to the following exponential function:

$$
I(t)=y_{\max }-\left(y_{\max }-y_{\min }\right) e^{\frac{-t}{\tau}}
$$

This function includes terms for the HS concentration at the plateau $\left(y_{\max }\right)$, the starting HS concentration $\left(y_{\min }\right)$, and the observed time constant $(\tau)$ for the increase in heparan sulfate on the cell surface. The time of half maximum, $t_{1 / 2}$, is the time required for $\mathrm{HS}$ abundance to reach a half-maximum on the EC surface by the relationship $t_{1 / 2}=\tau / \ln (2)$. Values for $\tau$ and the time of half maximum $\left(t_{1 / 2}\right)$ for the curve fit are tabulated in Table 1. The observed time constant, $\tau$ is found to be $19 \mathrm{~h}$ between 0 and $96 \mathrm{~h}$ of shear exposure, indicating that the heparan sulfate concentration on cells has reached its half maximum after $13 \mathrm{~h}$ and steady state (which is defined here as within $5 \%$ of $\left.y_{\max }\right)$ after $19 \mathrm{~h}$. The uncertainty in the experiments does not preclude the possibility that the HS abundance continues to increase modestly beyond $96 \mathrm{~h}$.

Representative epifluorescent microscopy images used to quantify HS are presented in Fig. 3. The distribution of HS is heterogeneous between individual cells as well as between multi-cellular areas of the monolayer. The distributions become more homogeneous with exposure to laminar flow (Fig. 3, top row). On cells that have been exposed to shear for $12 \mathrm{~h}$ and more, increased heparan sulfate staining is clearly visible.

\section{Endothelial Cells Align with the Flow Axis}

In order to determine the kinetics for cell alignment, phase contrast images were evaluated for changes in 


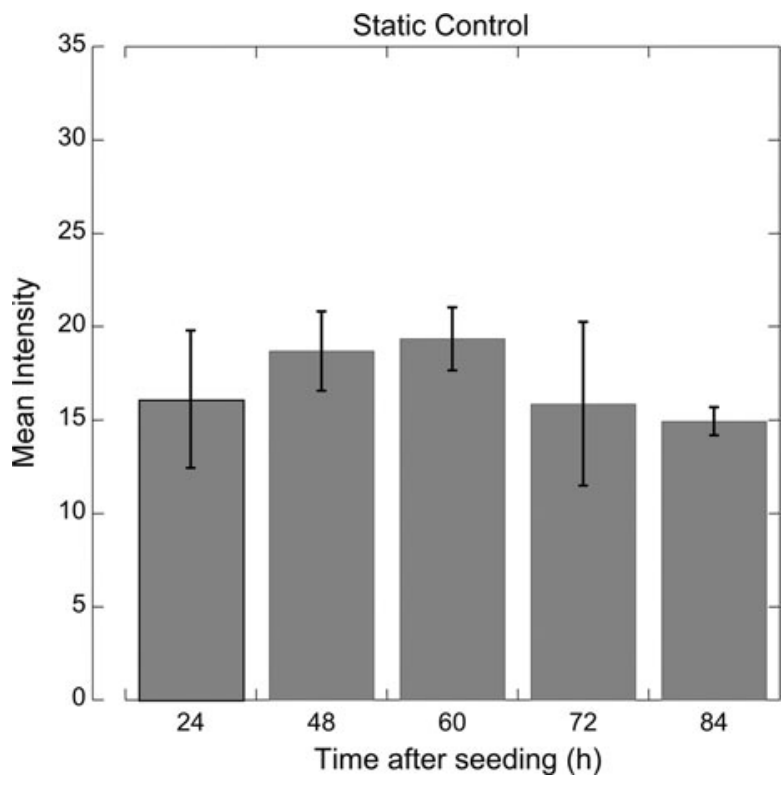

FIGURE 1. Heparan sulfate signal intensity from apical surface of static cultured HUVEC monolayers is constant up to $84 \mathrm{~h}$ after seeding. Grey bars represent the mean heparan sulfate fluorescence intensity of 4-16 monolayer images of different regions taken from 2 to 3 monolayers. No statistical significance between groups $(p<0.05)$.

circularity index and angle with respect to the flow vector. After $12 \mathrm{~h}$ of exposure to laminar flow, we documented that the cells have elongated from the rounded shape characteristic of statically cultured endothelial cells (mean circularity index $\mathrm{S}_{50}$ of 0.8 ) to a significantly lower circularity index of 0.5 (Fig. 4a). There is a significant difference in circularity between statically cultured EC and the $12 \mathrm{~h}$ data set $(p<0.001)$, which is not different from time points after $12 \mathrm{~h}$. No statistical differences exist among data sets between 12 and $96 \mathrm{~h}$ of laminar shear $(p=0.36)$.

After $12 \mathrm{~h}$ of exposure to laminar flow, EC alignment with the flow vector also had significantly increased $(p<0.01)$ from a median angle of $51^{\circ}$ to $32^{\circ}$ with respect to the flow vector (Fig. 4b). After $36 \mathrm{~h}$, a further significant decrease in the alignment angle is measured $\left(11^{\circ}\right.$, $p=0.005$ ). Between 36 and $96 \mathrm{~h}$, no significant difference in angle alignment is detected, indicating that alignment in the direction of the flow vector is complete after $36 \mathrm{~h}$. These data are in agreement with previously reported studies of cellular elongation and alignment ${ }^{34,44}$ and form the basis for comparison with cells subjected to heparan sulfate degradation.

\section{Heparan Sulfate is Restored 12 h After Heparinase Injury Under Laminar Flow}

The HUVEC monolayer was subjected to $24 \mathrm{~h}$ of laminar flow at $15 \mathrm{dyn} / \mathrm{cm}^{2}$ then briefly exposed to heparinase III (Fig. 5, $t=0$ ). Heparan sulfate was allowed to regenerate at $37{ }^{\circ} \mathrm{C}$ for discrete time periods under shear and then the relative abundance was measured using quantitative fluorescence microscopy. Data points in Fig. 5 have been normalized to the HS signal from static untreated HUVEC, which were grown in tandem with sheared endothelial cells to serve as a control. The control for the heparanase treatment is Fig. 2, the shear response without heparanase exposure. The control with no shear and no heparanase is a straight line at the unsheared static condition, which is taken as 1.0 for all of the related figures.

The rise in HS levels begins almost immediately; approximately $35 \%$ of the starting concentration of HS has returned after $3 \mathrm{~h}$, after which point a plateau emerges where the rate of HS increase slows until after $12 \mathrm{~h}$. After $24 \mathrm{~h}$, the data have reached steady state and no net increase in HS is observed for any time point thereafter. Based on a single exponential model, the observed time constant for the restoration of the heparan sulfate fraction of the glycocalyx is $11.8 \mathrm{~h}$ as shown in Fig. 5.

\section{Heparan Sulfate is Restored Within 20 h Under Static Condition}

Experiments analogous to those reported above for cells under shear stress were also conducted on static cultured EC by exposing them to heparinase III. It is found that static cultured EC regenerated heparan sulfate at a slower rate than cells exposed to high shear stress (Fig. 6). Following heparinase exposure, HS exhibited a similar trend as seen in high shear phenotype EC: an initial burst phase of regrowth within the first $6 \mathrm{~h}$, after which time HS levels reach steady state within $20 \mathrm{~h}$. The difference between static and flow conditions lies in the time required to reach a steady state equal to the HS level for each phenotype not exposed to heparinase. Fitting the data to a simple exponential equation yields an observed time constant of $20 \mathrm{~h}$. Thus, the time necessary for HS restoration on statically cultured cells is almost twice as long than the time required for restoration on endothelium under flow. This difference may be attributable to differences in the endocytosis and exocytosis rates for the two phenotypes,

Heparinase-treated endothelial cells in static culture were unable to regenerate apical heparan sulfate after $6 \mathrm{~h}$ when the endocytic/exocytotic pathways were inhibited by cold temperature (Fig. 7). Following heparinase injury, cells in static culture incubated for $6 \mathrm{~h}$ at $37^{\circ} \mathrm{C}$ were able to replenish $80 \%$ of the heparan sulfate that is present on untreated control monolayers. Low temperature completely abolishes the energydependent exocytosis of nascent heparan sulfate. These data also suggest that the HS turnover on EC follows 


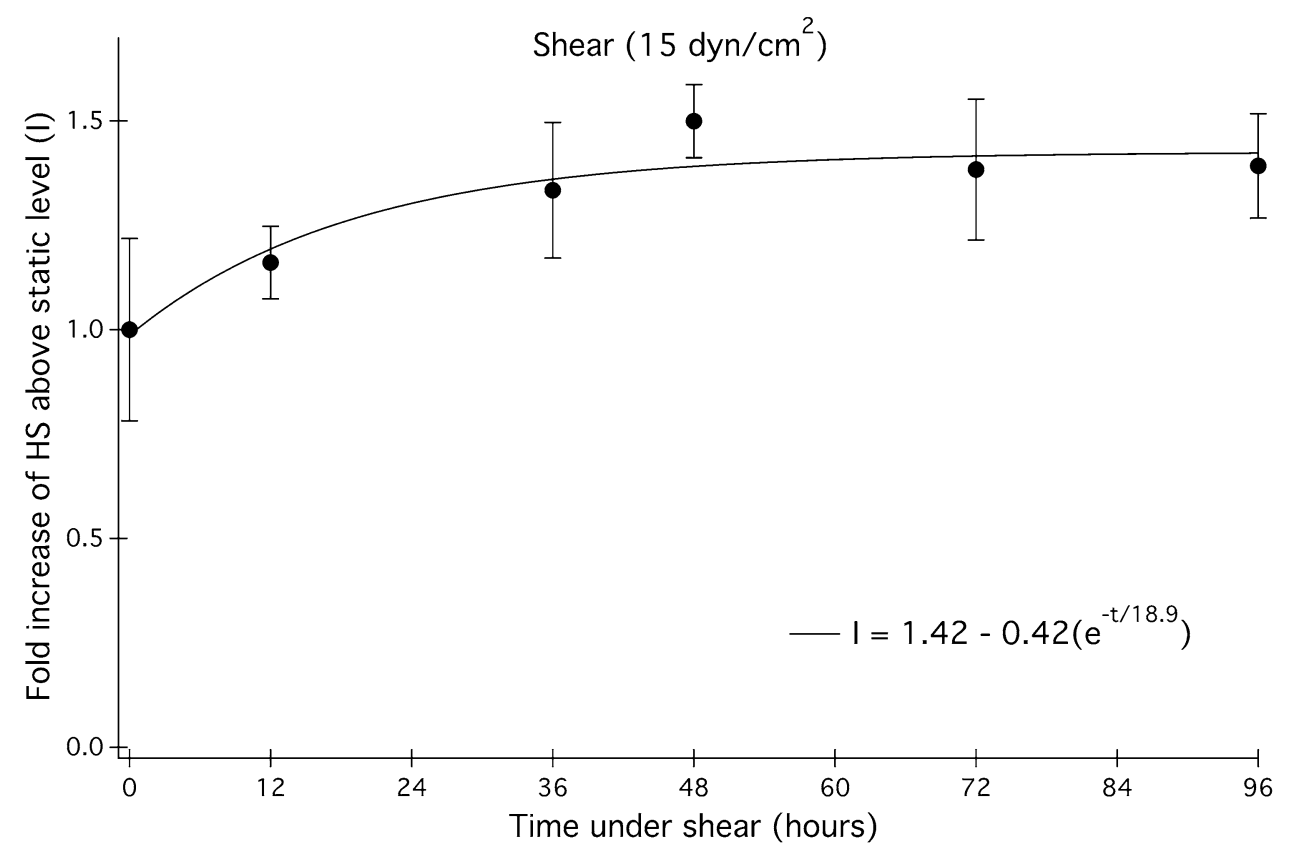

FIGURE 2. Heparan sulfate growth profile up to $96 \mathrm{~h}$ of shear. Data points are mean intensity of anti-heparan sulfate antibody captured by epifluorescence microscopy after discrete time periods of $15 \mathrm{dyn} / \mathrm{cm}^{2}$ shear stress. The observed rate constant is $0.053 \mathrm{~h}^{-1}$. Error bars are \pm standard deviation of 4-16 monolayer images of different regions taken from 2 to 3 monolayers.

TABLE 1. Observed time constants (tau) and halflife data $\left(t_{1 / 2}\right)$ for heparan sulfate growth on endothelial surface.

\begin{tabular}{lcr}
\hline Treatment group & $\tau^{\mathrm{a}}(\mathrm{h})$ & $t_{1 / 2}^{\mathrm{b}}(\mathrm{h})$ \\
\hline $15 \mathrm{dyn} / \mathrm{cm}^{2}$ & $18.9 \pm 10.2$ & 13.1 \\
$15 \mathrm{dyn} / \mathrm{cm}^{2}+$ Hpaselll & $11.8 \pm 3.2$ & 8.2 \\
0 dyn $/ \mathrm{cm}^{2}+$ Hpaselll & $20.2 \pm 0.4$ & 13.9 \\
\hline
\end{tabular}

a Values are \pm fit error.

${ }^{\mathrm{b}}$ Halflife values are calculated from $t_{1 / 2}=\tau / \ln (2)$.

an energy-dependent mechanism such as endocytosis and exocytosis.

\section{Cell Alignment Under Shear Stress is Arrested Following Heparinase Treatment}

HUVEC, cultured for $24 \mathrm{~h}$ under laminar flow, were briefly exposed to heparinase and were evaluated for changes in cell shape. In Fig. 8, the probability densities are given for the angle of the cell with respect to the flow vector and the circularity index of the cells. No significant difference was observed for either criterion after $3 \mathrm{~h}$ under shear following heparinase treatment when compared to control monolayers under laminar flow for the same duration of time (Figs. 8a, 8e). After $12 \mathrm{~h}$ following heparinase treatment, there is a significant increase in circularity of the cells when compared to control cells (Fig. 8b) that persists until $24 \mathrm{~h}$ following heparinase treatment (Fig. 8c), at which point the circularity has recovered to control values
(Fig. 8d). After $12 \mathrm{~h}$ following heparinase treatment, the angle of alignment to the flow vector is significantly decreased compared to control (Fig. 8f). By $24 \mathrm{~h}$, the alignment has recovered and there is no difference between heparinase treated EC and control monolayers (Figs. 8g, 8h).

\section{DISCUSSION}

The current results demonstrate that under 15 dyn/ $\mathrm{cm}^{2}$ of laminar flow, the endothelial heparan sulfate level increases by 1.4 -fold after $19 \mathrm{~h}$. The physiological significance of increased glycocalyx under flow has been demonstrated as regions of the carotid artery that are exposed to atheroprotective flow have a significantly thicker glycocalyx than regions under disturbed, or atheroprone, flow. ${ }^{10,39}$ In cultured endothelial cells, high shear stress increases production of the gene KLF2, ${ }^{40}$ whose downstream effects include increased production of proteoglycan 1, secretory granule (PRG1) and various sulfotransferases (SULF1, SULF2) ${ }^{29}$ that are present in the Golgi to modify nascent HS. Development of a thicker glycocalyx may serve the atheroprotective phenotype by providing steric hindrances to infiltrating cytokines and macrophages (reviewed in Lipowsky ${ }^{23}$ ).

Heparan sulfate fluorescence signals, collected at various time points between inception and $72 \mathrm{~h}$ following the application of shear stress, were fit to an exponential function that describes the observed cell 

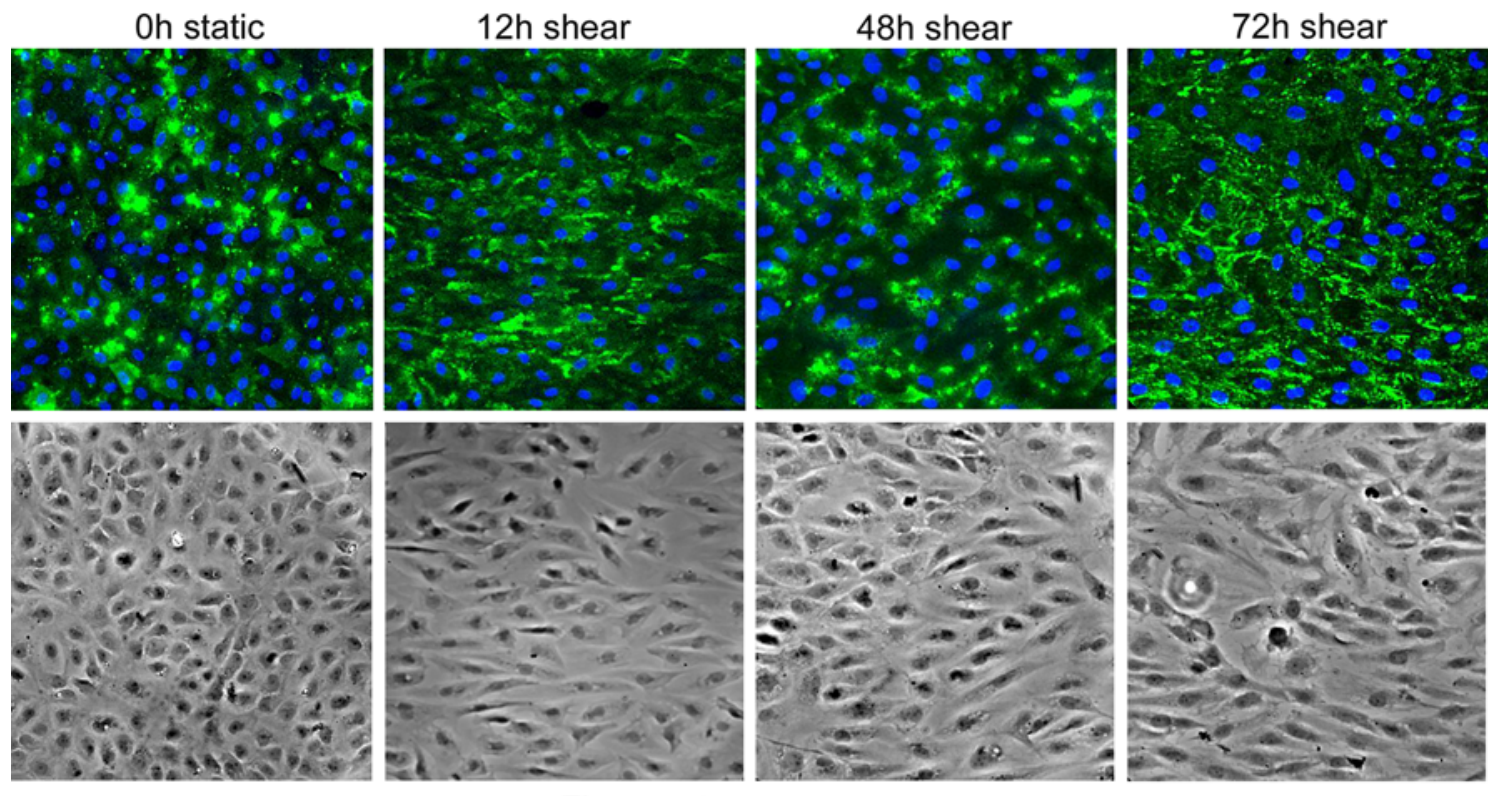

Flow vector

FIGURE 3. HUVEC monolayer staining for anti-heparan sulfate after 12,48 , and $72 \mathrm{~h}$ of laminar flow $\left(15 \mathrm{dyn} / \mathrm{cm}^{2}\right)$. Top row, antiheparan sulfate antibody in green, cell nuclei in blue. Bottom row, corresponding phase contrast image.

(a)

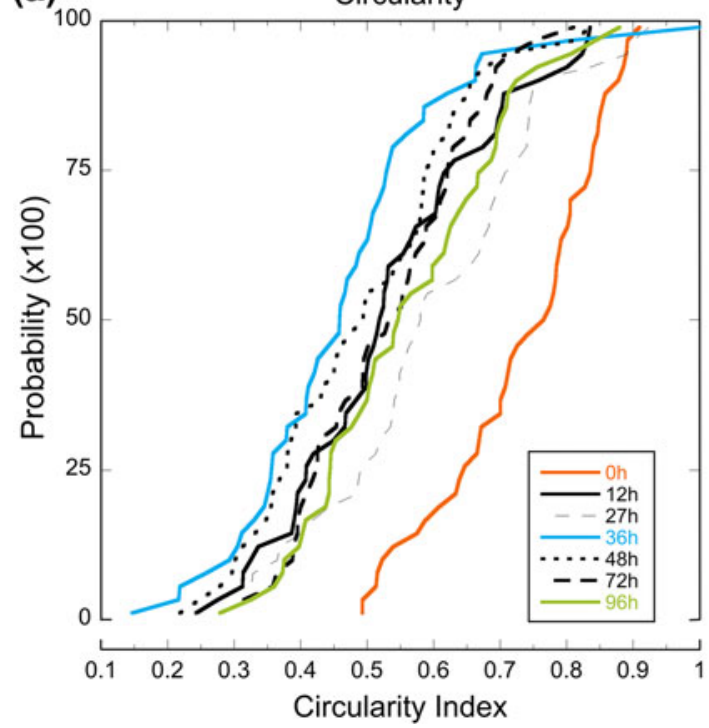

(b)

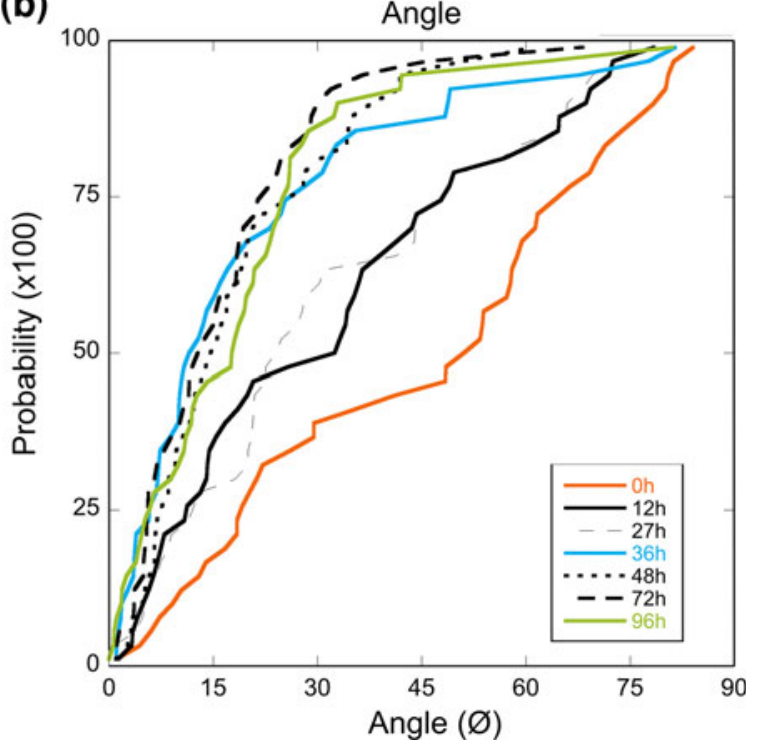

FIGURE 4. Cumulative probability distributions for cells after time exposed to laminar flow $\left(15 \mathrm{dyn} / \mathrm{cm}^{2}\right) \mathrm{moving}$ from static $(0 \mathrm{~h})$ to 4-day shear $(96 \mathrm{~h})$ phenotype. (a) Circularity index decreases significantly for cells after $12 \mathrm{~h}$ of shear $(p<0.001, N=45)$ but no further reduction in the circularity index occurs at subsequent time points. (b) Angle of alignment to the flow vector increases significantly after $12 \mathrm{~h}$ following heparinase treatment $(p=0.01, N=45)$ and again after $36 \mathrm{~h}$ of $\operatorname{shear}(p=0.005, N=45)$.

surface HS as a function of time and the starting and plateau concentrations of cell surface HS (Fig. 2). The time constant for the observed upregulation of HS following shear onset is $18.8 \mathrm{~h}$. If the data were extended past 4 days, the HS levels may continue to rise, as is observed when EC are exposed to shear stress for 7 days and a 2-fold increase in HS is seen. ${ }^{22}$
The rate of the decrease of the circularity index and alignment angle follows the time course for HS upregulation under laminar shear stress (Fig 4). Circularity is significantly decreased, indicating significant cell elongation, after $12 \mathrm{~h}$ (Fig 4a) and the angle of alignment to the flow vector has also significantly decreased after $12 \mathrm{~h}$ and reaches its maximal alignment 
after 36 h (Fig 4b). Interestingly, flow conditioned EC exposed to heparinase temporarily increase circularity at $12 \mathrm{~h}$ after heparinase treatment (Fig. 8b) and the angle of alignment also temporarily increases by $12 \mathrm{~h}$ (Fig. 8f). These results indicate that the loss of the ability of cells to sense shear causes them to become more round and disorganized. In these experiments, the cells are regenerating their HS glycocalyx at the same time the loss of alignment is taking place. Thus, there is a first change towards the static conditioned EC followed by a return to the atheroprotective phenotype following restoration of the glycocalyx (Figs. 8c-8d and 8g-8h). EC without heparan sulfate behave similarly to high shear phenotype EC that are experiencing a sudden loss of shear stress. Remuzzi et $a l .{ }^{34}$ have demonstrated that when flow is removed from high shear cultured EC, the mean elongation of the cells persists for 3-4 h, after which point the decrease in the cell's aspect ratio is monotonic with time. ${ }^{34}$ In Figs. $8 \mathrm{c}$ and $8 \mathrm{~d}$, the circularity of the cells has made a significant recovery after $24 \mathrm{~h}$ and makes a full recovery after $48 \mathrm{~h}$, indicating that the restoration of HS restores the ability of the cell to sense and respond to an imposed flow vector. The changes in EC alignment are also returned to pre-treatment conditions within $24 \mathrm{~h}$ (Figs. 8g, 8h), again reflecting the time scale necessary for static cultured cells to respond to changes in local flow.

Our observations of a glycocalyx with a heparan sulfate moiety that is removed by heparinase and regrows in 1-2 days depending on the flow conditions is contradictory to the report by Potter and Damiano that endothelial cells in culture do not posses any glycocalyx. ${ }^{31}$ In addition to the detection of a robust heparin sulfate layer in vitro, we also find that characteristic functions of the endothelial cells to align with the flow direction and change to an elongated form become lost when the glycocalyx HS is removed and the mechanisms supporting these responses are restored when the HS moiety is restored. The apparent absence of a glycocalyx in earlier studies ${ }^{31}$ may have resulted from their method of enzyme delivery. Enzymes were delivered and circulated in medium lacking serum protein, which Adamson and Clough ${ }^{1}$ have shown to collapse the glycocalyx. Also, their in vitro model was a small long cylindrical cavity in a collagen gel, and the ability of this model to reproduce other known features of endothelial response reported in previous papers has not been demonstrated. Recent measurements by Ebong et al. ${ }^{12}$ show significant glycocalyx on in vitro endothelial cell cultures. Additional data are now available from confocal microscopy that clearly identify the apical glycocalyx layer in vitro and measure HS thickness in excess of $0.5 \mu \mathrm{m}$. Furthermore, the specificity of hyaluronidase for hyaluronic acid has not been proven; therefore, its ability to completely remove the glycocalyx, which is composed of a variety of polysaccharides, is a surprising result. Gao and Lipowsky ${ }^{17}$ report that heparanase reduces the volume of the glycocalyx by $60 \%$ and hyaluronidase treatment results in a $20 \%$ reduction in total glycocalyx volume. The remainder of some glycocalyx

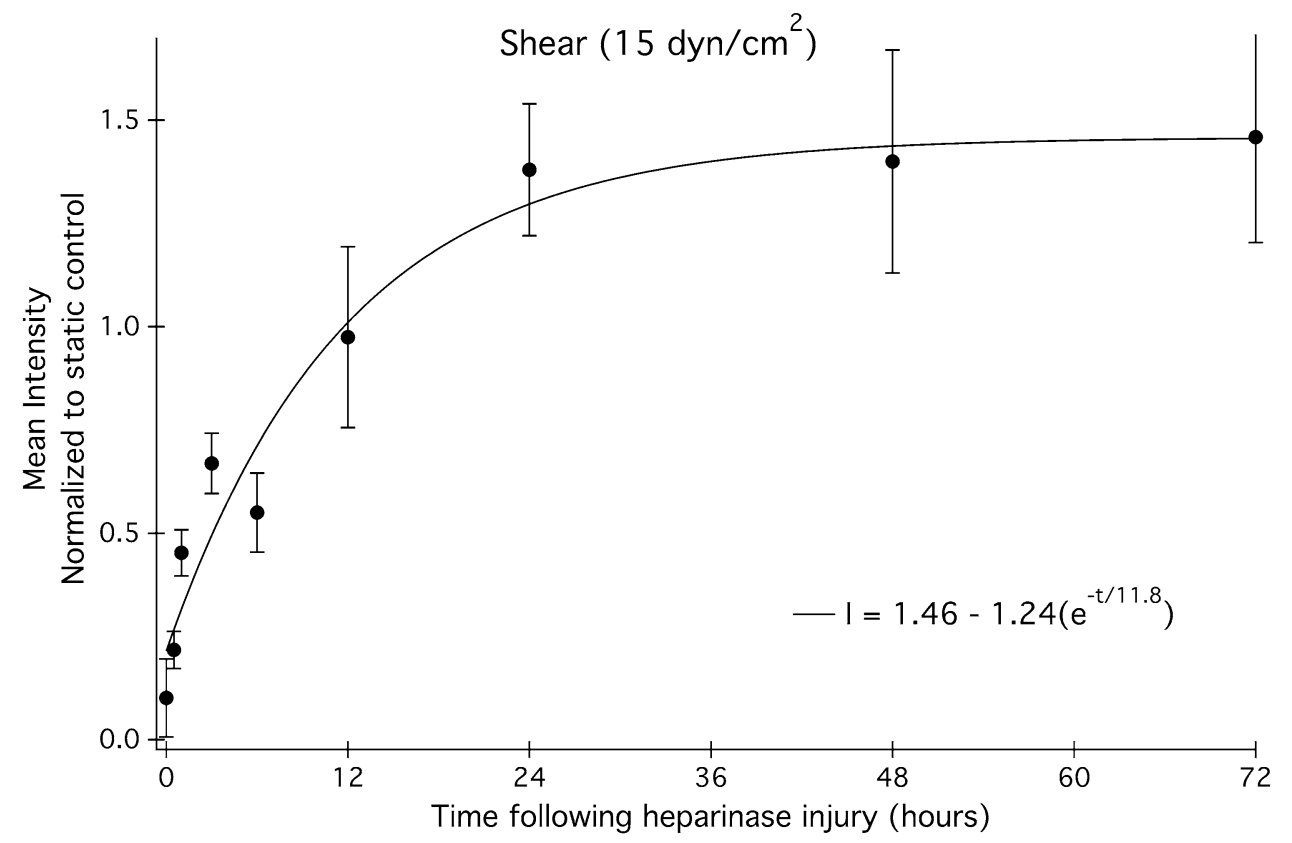

FIGURE 5. Heparan sulfate regrowth profiles under laminar flow $\left(15 \mathrm{dyn} / \mathrm{cm}^{2}\right)$ following heparinase treatment at time 0 . Each point represents mean fluorescence intensity of HS from 4 to 9 images. The observed time constant, tau, is $11.8 \pm 3.2 \mathrm{~h}$. 


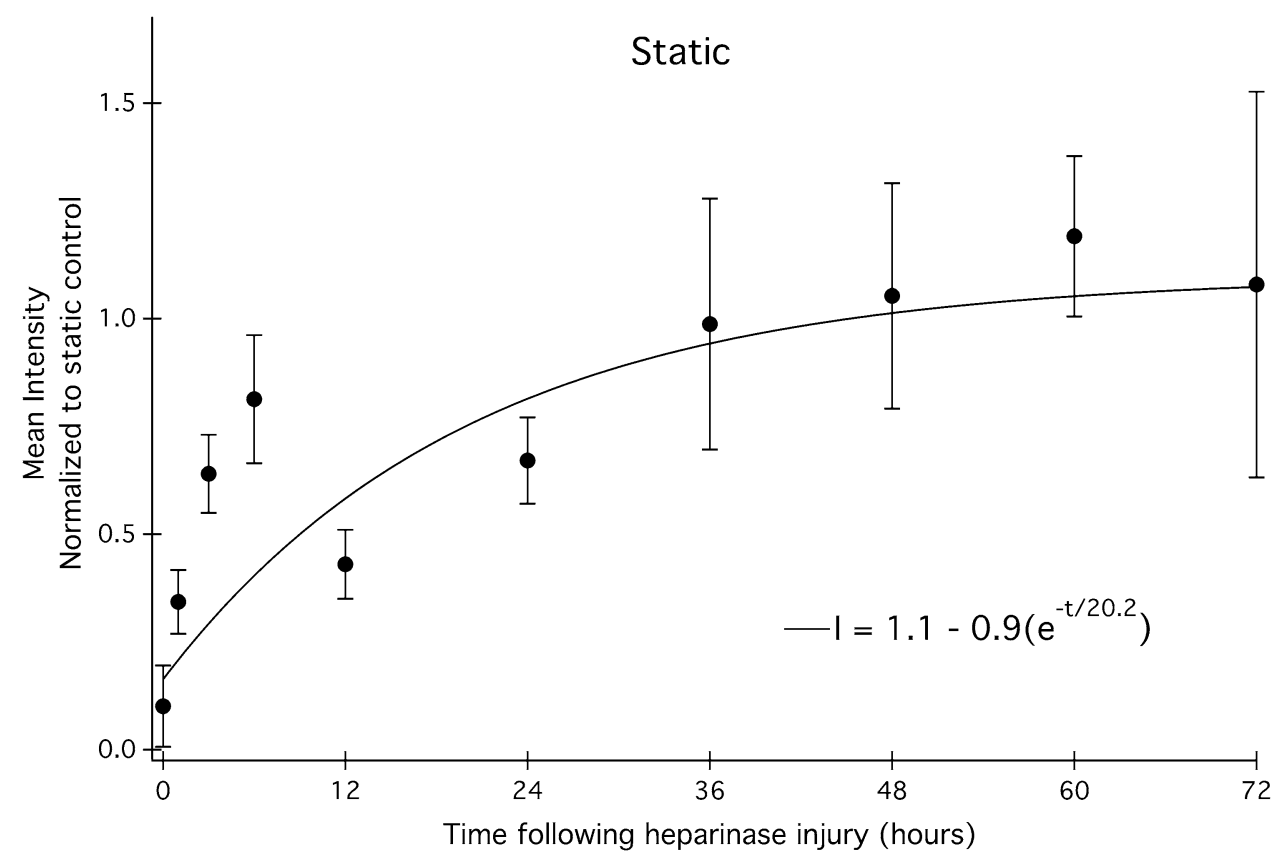

FIGURE 6. Heparan sulfate regrowth profiles under static conditions following heparinase treatment at time 0 . Each point represents mean fluorescence intensity of HS from 4 to 9 images. The observed time constant, tau, is $20.2 \pm 0.4 \mathrm{~h}$.

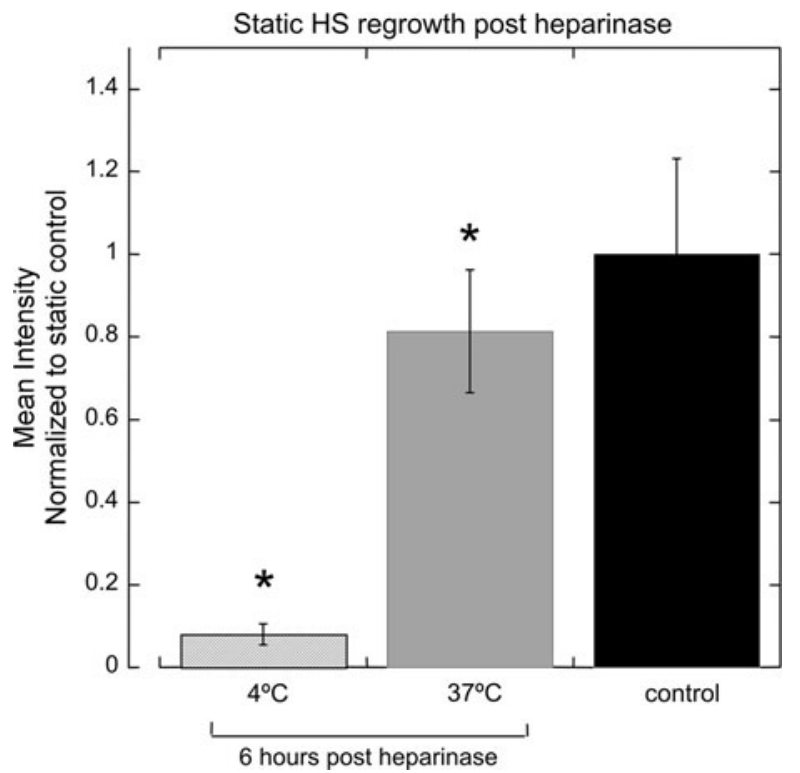

FIGURE 7. Heparan sulfate regeneration on cell surface is exocytosis-dependent. For $6 \mathrm{~h}$ following heparinase exposure, heparan sulfate exocytosis is diminished at $4{ }^{\circ} \mathrm{C}$ (shaded bar) and actively restores heparan sulfate at $37^{\circ} \mathrm{C}$ (grey bar). Heparinase treatment groups are normalized to the static control condition (black bar) receiving no heparinase. ${ }^{*} p<0.05$ difference from control. $N \geq 4$.

would be expected if only certain components are being targeted. We demonstrate that in vitro HUVEC can produce a physiologically responsive glycocalyx, as these cells align in the direction of flow, and that a key component of that glycocalyx is restored within a physiologically relevant time frame following acute enzymatic removal.

The overall shapes of the kinetic profiles of both shear-conditioned and static cells recovering from heparinase injury have similar biphasic properties. Within $6-12 \mathrm{~h}$, HS levels have recovered to $60-80 \%$ of their final concentration and the rapid increase in HS suggests that the transit time between newly synthesized HS and the Golgi apparatus is fast under both culture conditions. There is evidence to support a quick turnover rate for heparan sulfate. Within $4 \mathrm{~h}$ following a pulse-chase experiment, Carter et al. ${ }^{8}$ show that only $35 \%$ of the initial $\left[{ }^{3} \mathrm{H}\right]$ glucosamine label in the glycocalyx of HMEC-1 endothelial cells remains, suggesting that heparan sulfate is quickly removed from the cell surface and replaced with new material. In Figs. 5 and 6 , there is an initial burst phase of heparan sulfate regrowth, after which point the high shear profile rises and plateaus within $12 \mathrm{~h}$; however, the corresponding rate of regrowth under static conditions is much slower. The biphasic nature of the regrowth profiles of both phenotypes may indicate a change in the dominant HS regrowth mechanism after $6 \mathrm{~h}$. This suggests that it is possible that there is a transition in the early injury response from rapid vesicle release from the Golgi to a dominant recycling of endosomes containing unmodified syndecans back to the cell surface.

Our proposed model describes the active regeneration and removal of heparan sulfate on the apical 

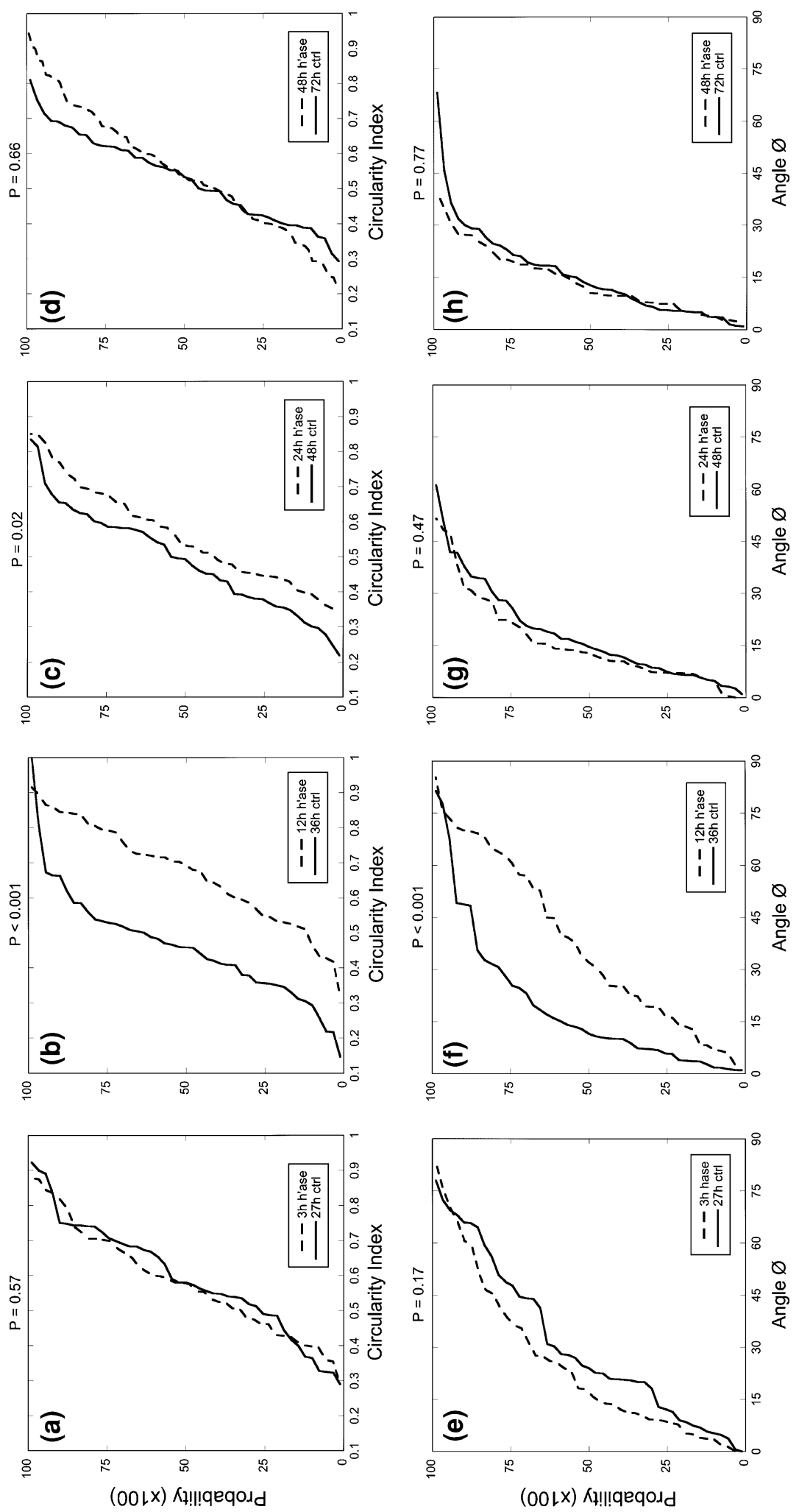

FIGURE 8. Cumulative probability distributions for heparinase-treated EC under laminar flow (15 dyn/ $\left.\mathrm{cm}^{2}\right)$ measuring circularity index (a-d) and angle of alignment (e-h). Circularity indices for cells under laminar flow for (a) 3, (b) 12, (c) 24, and (d) $48 \mathrm{~h}$ following heparinase treatment and time-matched controls. Significant differences are shown after 12 and $24 \mathrm{~h}$ under laminar flow following enzymatic degradation. Angle of alignment data are given for cells under laminar flow for (e) 3 , (f) 12, (g) 24, and (h) $48 \mathrm{~h}$ following heparinase treatment and time-matched controls. Significant differences are shown at $12 \mathrm{~h}$ following heparinase treatment. ( $N=\mathbf{4 5}$ cells per group from 3 separate monolayers). 
surface of endothelial cells and is presented in Fig. 9. Heparan sulfate proteoglycans (HSPG) are produced de novo from vesicles that bud from the trans-Golgi compartment and appear on the cell surface within 12 min. ${ }^{38}$ Heparan sulfate is then either shed from the surface or internalized into the cell. ${ }^{4}$ Reported rates for internalization vary from $30 \mathrm{~min}^{38}$ to $4 \mathrm{~h},{ }^{43}$ but it is generally agreed that the mode of entry is via a clathrin- and caveolae-independent mechanism that likely involves macropinocytosis ${ }^{27}$ and/or lipid rafts. ${ }^{16,21}$ Following endocytosis, it has been reported that HSPG are swiftly localized to the late endosome, ${ }^{30}$ however, there are reports of a rapid recycling mechanism that may involve early endosomes. ${ }^{4,38,45}$

Membrane recycling may balance the endocytic removal of surface membrane to maintain cell size and return unmodified proteins and lipids to the surface. Bai et al. ${ }^{4}$ have reported syndecan recycling and in kinetic studies, recycling was shown to be a dynamic process that occurs within minutes. ${ }^{38}$ Takeuchi et al. ${ }^{38}$ have measured syndecan turnover kinetics and calculate that cell surface heparan sulfate recycles to and from an intracellular compartment approximately 10 times before degradation under low calcium conditions. Zimmermann et al. ${ }^{45}$ have identified a role for syntenin, which can bind $\mathrm{PIP}_{2}$ and syndecan, in the release of syndecans from ADP-ribosylation factor 6 (Arf6)associated recycling endosomes. A mechanism for heparan sulfate recycling is included in our model as it may be a key component of endothelial homeostasis.

We assume that the concentration of HS in the surface glycocalyx layer is governed by five pathways: (1) uninhibited HS transport of HS-containing vesicles from the Golgi to the membrane surface of the cell; (2) shedding of HS and HS-binding transmembrane proteins from the surface to the plasma; (3) endocytosis; (4) exocytosis; and (5) lysosomal degradation within the cell. Endocytosis and exocytosis are active transport processes which depend, respectively, on the surface concentration and the concentration of HS in vesicles diffusing freely within the cytoplasm. In addition to the three dynamic processes (1), (3), and (4) that are associated with the cell membrane, we include two additional loss mechanisms: (2) shedding of the HS from the surface from circulating cytokine cleavage and (5) the loss of cytoplasmic vesicles through endosomal activity. The model closely resembles the transport processes described by Gross and Lodish for the degradation of erythropoietin. ${ }^{19}$ The following equations describe the change in surface heparan sulfate over time based on these four mechanisms:

$$
\begin{aligned}
& \frac{d\left[\mathrm{HS}_{\text {surface }}\right]}{d t}=k_{\mathrm{golgi}}\left[\mathrm{HS}_{\mathrm{golgi}}\right]+k_{\mathrm{exo}}\left[\mathrm{HS}_{\mathrm{ee}}\right] \\
& -k_{\text {endo }}\left[\mathrm{HS}_{\text {surface }}\right]-k_{\text {shed }}\left[\mathrm{HS}_{\text {surface }}\right]
\end{aligned}
$$

$$
\begin{aligned}
\frac{d\left[\mathrm{HS}_{\mathrm{ee}}\right]}{d t}= & k_{\mathrm{endo}}\left[\mathrm{HS}_{\text {surface }}\right]-k_{\mathrm{exo}}\left[\mathrm{HS}_{\mathrm{ee}}\right]-k_{\mathrm{le}}\left[\mathrm{HS}_{\mathrm{ee}}\right] \\
& \frac{d\left[\mathrm{HS}_{\mathrm{le}}\right]}{d t}=k_{\mathrm{le}}\left[\mathrm{HS}_{\mathrm{ee}}\right]-k_{\mathrm{lys}}\left[\mathrm{HS}_{\mathrm{le}}\right] \\
& \frac{d\left[\mathrm{HS}_{\mathrm{lys}}\right]}{d t}=k_{\mathrm{lys}}\left[\mathrm{HS}_{\mathrm{le}}\right]-k_{\circ}\left[\mathrm{HS}_{\mathrm{lys}}\right]
\end{aligned}
$$

All concentrations $\left[\mathrm{HS}_{\mathrm{xx}}\right]$ are referenced to a unit surface area of the cell, i.e., the cytoplasm is considered well mixed to this operation. Subscript "ee" refers to the cytoplasmic space (early endosomes), and "le" refers to the late endosomes of the terminal lysis pathway. Equation (1) describes the change in cell surface HS as a function of HS production from the Golgi and also replenishment from early endosomes via exocytosis, its removal via endocytosis and shedding, and its replenishment by exocytosis of early endosomes within the cytoplasm. Equations (2) and (3) track intracellular HS in early and late endosomes, respectively, and Eq. (4) describes the process of transfer from late endosomes to lysosomes and the loss of the degradation products from the lysosomes. The rate constants that are used in the model are listed in Table 2 and Table 3 contains the initial and final concentrations of each compartment described by Eqs. (1)-(4). The model predictions of heparan sulfate regrowth are shown alongside experimental data in Figs. $10 \mathrm{a}$ and $10 \mathrm{~b}$ for the static and shear conditions, respectively.

Several assumptions were made in order to develop a sufficiently simple and useful model, as shown in Figure 9. The first assumption is that all labeled heparan sulfate behaves identically. The model for the intracellular behavior of HS was based upon on the shape of the curve that describes [ $\mathrm{HS}_{\text {surface] }}$, which was obtained experimentally. The antibodies that targeted cell surface HS did not differentiate between HS on syndecans or glypicans so we do not differentiate between different transmembrane proteoglycans. Second, the rate of HS release from the Golgi is held constant while the rates of membrane vesicles trafficking to the surface is varied, depending on whether the cell has the high shear or static phenotype. Evidence for this behavior comes from Arisaka et al., ${ }^{3}$ wherein high shear stress did not change the synthesis rate of HS but did increase the total rate of transport of synthesized GAG to the cell surface. Last, we assume that HS production is complete as it exits the Golgi, which has been established as the location of HS biosynthesis and nascent enzymatic alteration (reviewed by Esko and Lindahl ${ }^{13}$ ). We acknowledge that the glycocalyx is a dynamic layer subject to constant real-time modifications in response to 


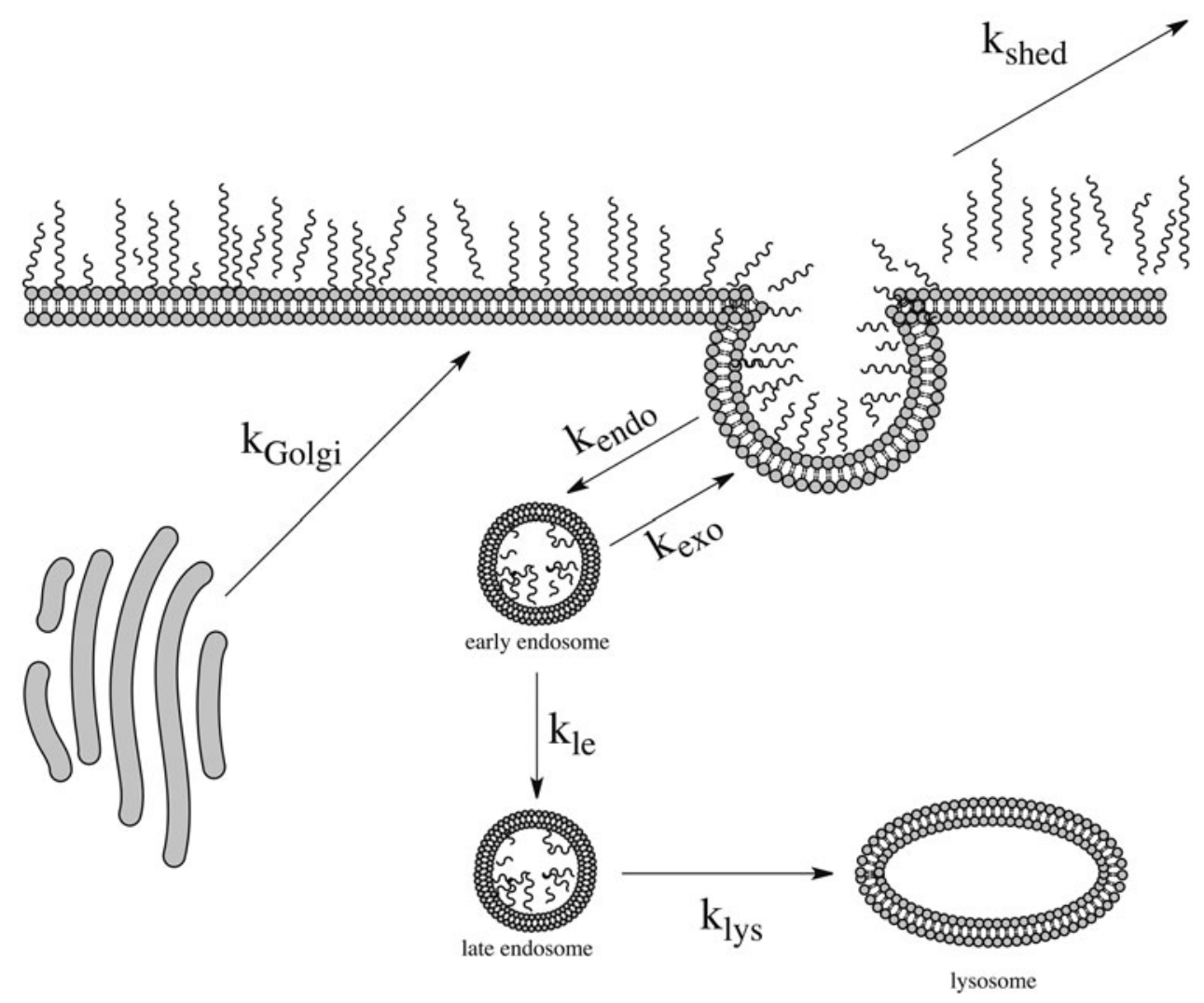

FIGURE 9. Kinetic model of heparan sulfate turnover from cell surface. Heparan sulfate concentration on cell surface is modeled as a function of the rate of HS production from the Golgi apparatus $\left(k_{\mathrm{golgi}}\right)$, endocytosis $\left(k_{\text {endo }}\right)$ from the cell surface, and exocytosis from recycling vesicles $\left(k_{\text {exo }}\right)$ and from the late endosome $\left(k_{\text {endole }}\right)$.

TABLE 2. Model-derived rate constants.

\begin{tabular}{llll}
\hline & & \multicolumn{1}{c}{ Rate constant $\left(\mathrm{h}^{-1}\right)$} \\
Same & \multicolumn{1}{c}{ Process } & \multicolumn{1}{c}{ Static } \\
\hline$k_{\text {Golgi }}$ & de novo HS production from Golgi apparatus & 0.96 & 0.96 \\
$k_{\text {exo }}$ & HS exocytosis from recycling vesicles & 0.075 & 0.05 \\
$k_{\text {endo }}$ & HS endocytosis & 0.025 & 0.05 \\
$k_{\text {le }}$ & HS trafficking to late endosome & 0.01 & 0.01 \\
$k_{\text {lys }}$ & HS trafficking to lysosome & 0.01 & 0.01 \\
$k_{\text {shed }}$ & HS cell surface shedding & 0.10 & 0.033 \\
$k_{\text {deg }}$ & HS release from lysosome & 0.005 & 0.005 \\
\hline
\end{tabular}

environmental changes, however, these details are beyond the scope of the model.

The static parameters outlined in Tables 2 and 3 satisfy the conditions set forth by Bai et al. ${ }^{4}$ that quantifies heparan sulfate at the static endothelial surface, inside the cell, and in the medium. Using pulse-chase experiments with ${ }^{35} \mathrm{~S}$ radiolabel, Bai et al. ${ }^{4}$ determine that the steady-state ratio for HS inside the cell to the surface is $2: 1$ and similarly reveal that in the untreated wild-type cell, the concentrations of HS on the surface and in the lysosome are approximately equal. While these numbers are not given explicitly in the text, they may be extrapolated by integration of the liquid chromatograms. The ratios derived from Bai et l. $^{4}$ are mirrored in the concentration of HS in each compartment of the model after steady state is reached (Fig. 11). For the surface concentration, that time is $20.2 \mathrm{~h}$ however, for the lysosomal compartment the time to reach steady state is extended because of the time required to bring the upstream early and late endosome compartments to full equilibrium.

An evaluation of the model for EC under high shear is shown in Fig. 12. To increase the output of HS to the surface, the de novo production of HS in the Golgi was increased, while its rate of trafficking to the surface remains unchanged, in agreement with findings 
TABLE 3. Initial and final HS abundances as model parameters.

\begin{tabular}{|c|c|c|c|c|c|}
\hline \multirow[b]{3}{*}{ Name } & \multirow[b]{3}{*}{ Compartment } & \multirow{2}{*}{\multicolumn{2}{|c|}{$\begin{array}{c}\text { Initial concentration }^{\mathrm{a}, \mathrm{b}} \\
t=0\end{array}$}} & \multirow{2}{*}{\multicolumn{2}{|c|}{$\frac{\text { Steady state concentration }^{\mathrm{a}}}{t=1000 \mathrm{~h}}$}} \\
\hline & & & & & \\
\hline & & Shear & Static & Shear & Static \\
\hline$\left[\mathrm{HS}_{\mathrm{Golgi}}\right]$ & Golgi apparatus & 0.155 & 0.05 & 0.155 & 0.05 \\
\hline$\left[\mathrm{HS}_{\mathrm{ee}}\right]$ & Early endosome & 0.4 & 0.4 & 0.4 & 0.4 \\
\hline$\left[\mathrm{HS}_{\mathrm{le}}\right]$ & Late endosome & 0.4 & 0.4 & 0.4 & 0.4 \\
\hline$\left[\mathrm{HS}_{\text {lys }}\right]$ & Lysosome & 0.85 & 1.23 & 0.85 & 1.23 \\
\hline$\left[\mathrm{HS}_{\text {surface }}\right]$ & Cell surface & 0.1 & 0.1 & 1.45 & 1.10 \\
\hline
\end{tabular}

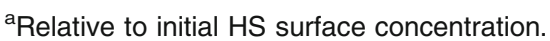

${ }^{\mathrm{b}}$ Following heparinase treatment.
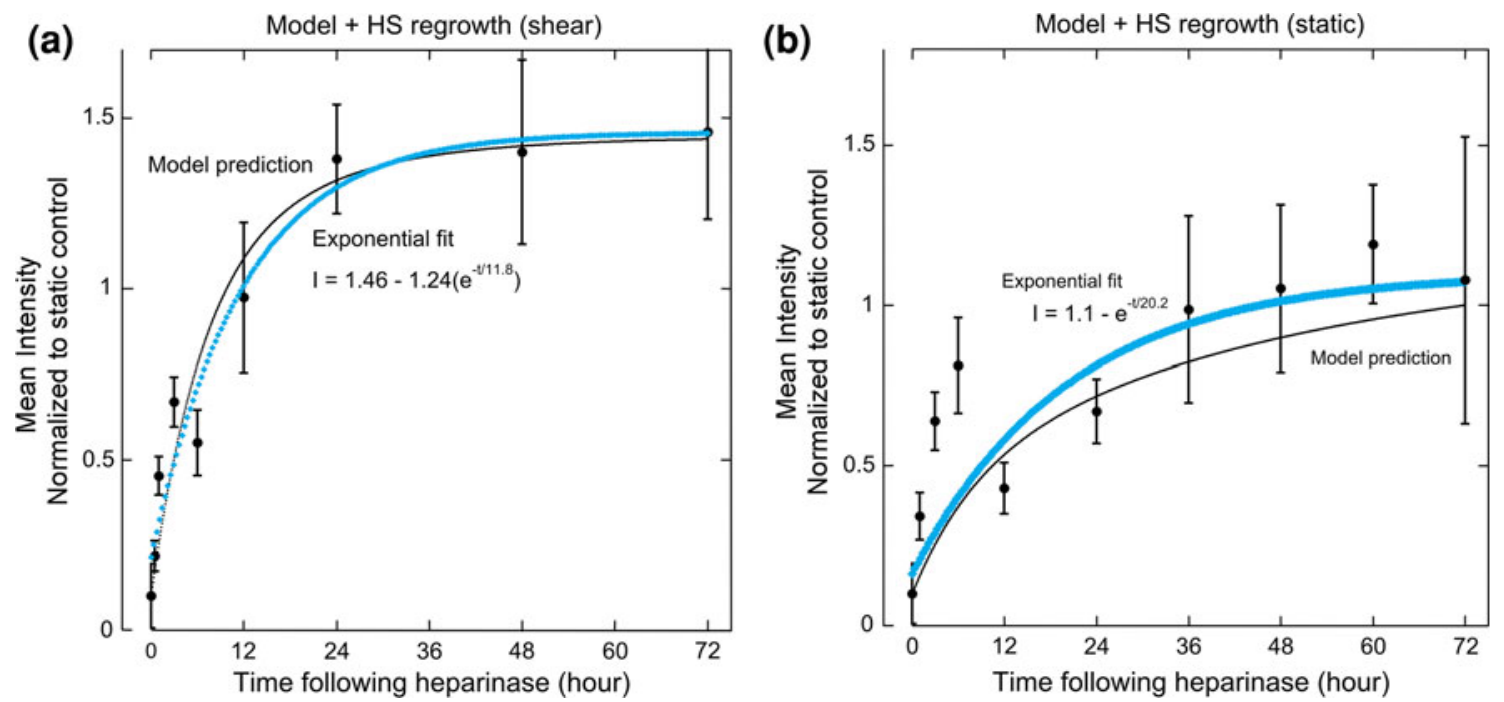

FIGURE 10. Model predictions closely follow experimental data. Model prediction (thin black line) is plotted with experimental data (filled circles) from heparan sulfate concentration following heparinase treatment for (a) static and (b) shear-conditioned HUVEC (15 dyn/ $\left.\mathrm{cm}^{2}\right)$. Exponential fit to experimental data is represented by the thick blue line.

from Arisaka et al. $^{3}$ The plateau abundance of heparan sulfate is reached more quickly in this model due to a 3 -fold increase in shedding under shear conditions and a concurrent increase in trafficking of HS from the Golgi to the surface. While it is clear in the literature that shear stress induces shedding under ischemic conditions (reviewed by Mulivor et $a .^{24}$ ), the shedding rate has not been explored under high shear stress for otherwise normal endothelium. An increase in the ratio of exocytosis to endocytosis from 1:1 to $3: 1$ for this model decreases the time necessary to reach steady state on the EC surface. The HS concentration of the intracellular compartment of high shear EC is approximately equal to that of the static EC, which complements the observation by Arisaka et al. ${ }^{3}$

A close examination of the ability of the model to fit the data for both the static cell recovery and the sheared cell recovery suggests that there may be an additional unmodeled mechanism acting at short times to release HS-containing vesicles to the surface to recover HS much faster than the current model can predict. This would imply that some store of HS-containing vesicles, either in the cytoplasm or in the Golgi themselves, are liberated in the event that the external glycocalyx layer is compromised. It will be an interesting challenge to attempt to identify this unknown HS source that appears in the recovery process.

Shear induced elongation and alignment with the flow vector are attributed in part to the role of heparan sulfate in mechanotransduction. ${ }^{44}$ Here the rate of alignment of the cells to the flow axis is evaluated in tandem with shear-mediated increases in luminal heparan sulfate. Endothelial cells under shear stress begin to align with the flow vector within $12 \mathrm{~h}$, but have not completely aligned until $36 \mathrm{~h}$ have passed (Fig. 5b). The circular cell shape that is characteristic of statically cultured endothelial cells has significantly elongated after $12 \mathrm{~h}$, which is on par with significant increases in 


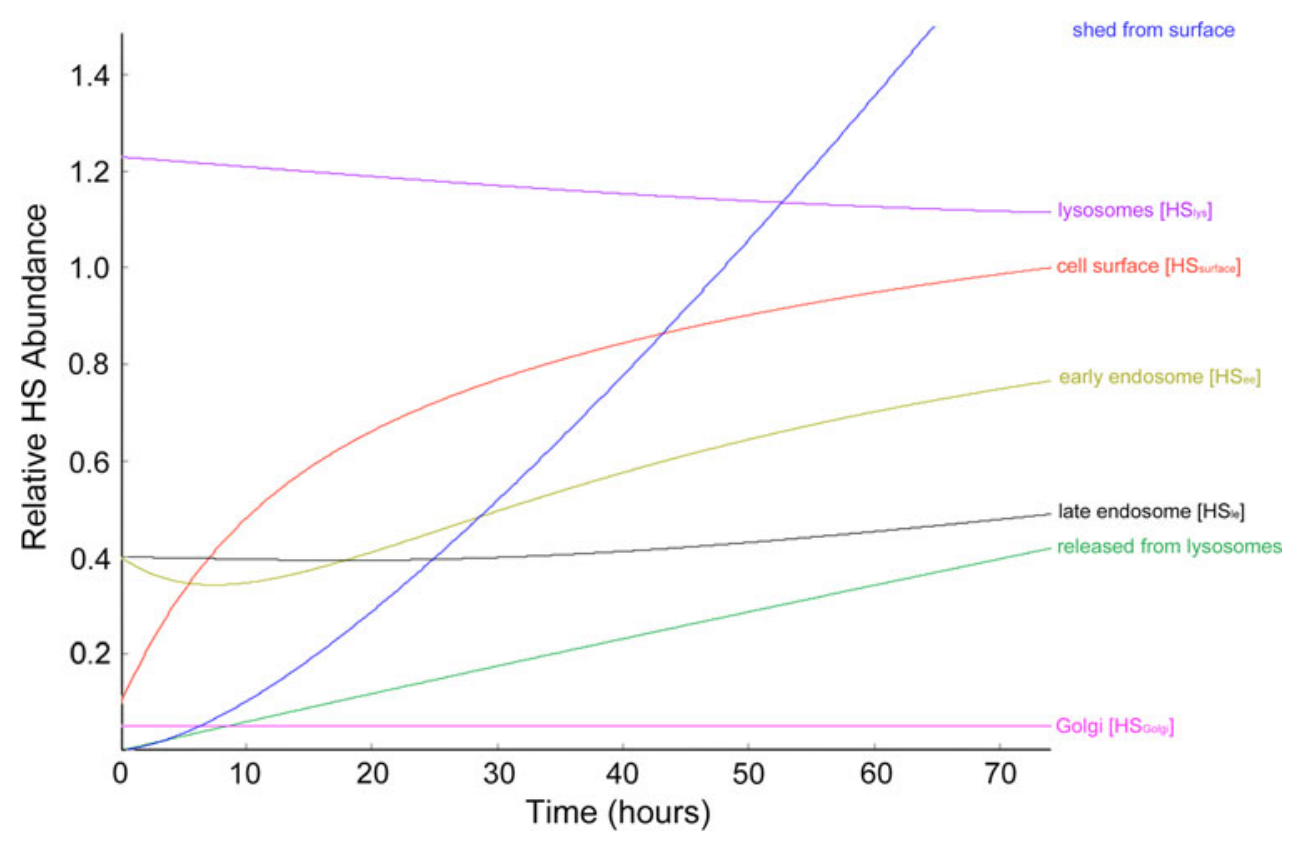

FIGURE 11. Model prediction for HS trafficking and cell surface regrowth in static phenotype EC following heparinase treatment.

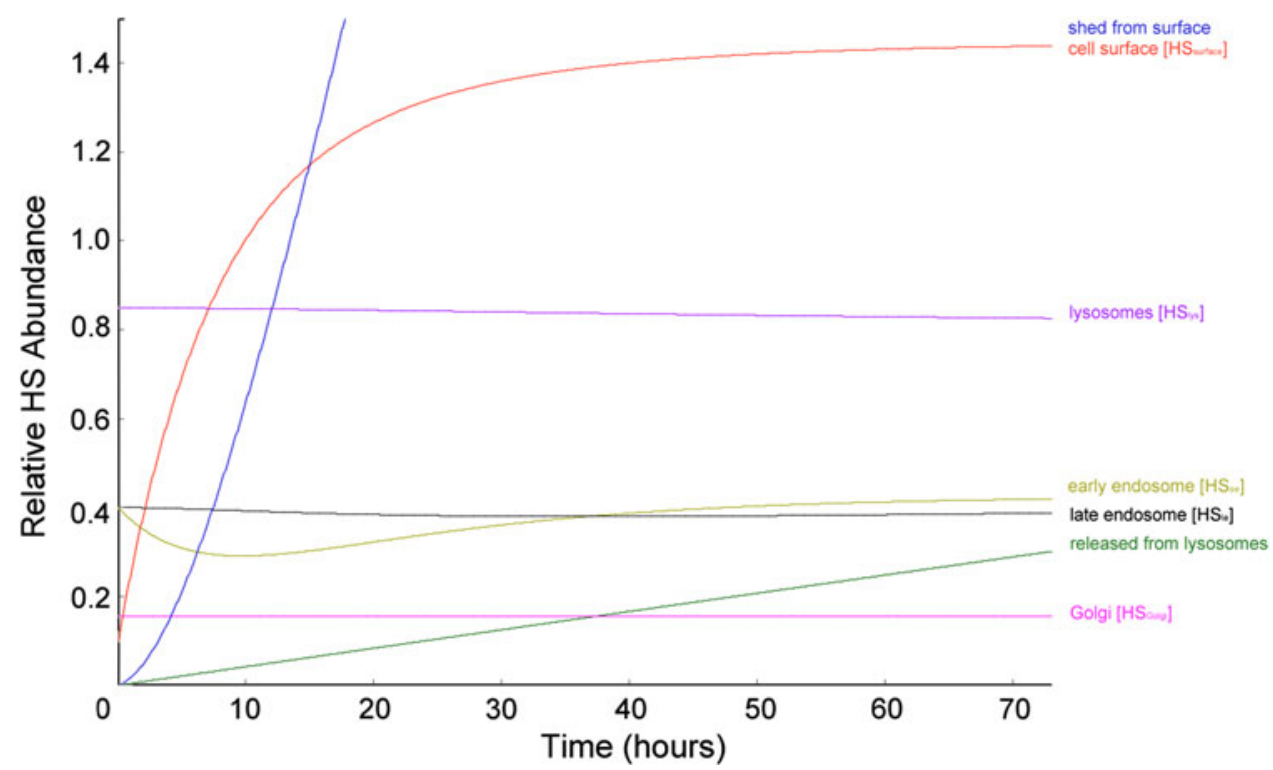

FIGURE 12. Model prediction for HS trafficking and cell surface regrowth in shear phenotype EC following heparinase treatment.

heparan sulfate as the cells move from static to flow condition. These results indicate that cell motility is a slower event than elongation, but both phenomena reach a plateau after $36 \mathrm{~h}$. Brief removal of heparan sulfate does not have an effect on cell shape or motility, but it is possible that prolonged exposure to enzymatic degradation could cause the cells to revert to a static phenotype with an extended loss of the ability to sense and respond to mechanical stimuli.

\section{CONCLUSIONS}

In this work, we demonstrate quantitatively the increases of heparan sulfate on the endothelial surface in response to high shear stress and validate the results using quantitative fluorescence microscopy. We present a time course for the regeneration of heparan sulfate on the endothelial cell surface following heparinase injury and correlate that recovery course 
with cell elongation mechanics, thus demonstrating an active and relevant glycocalyx present on cultured endothelium. A model for the uptake and release of apical heparan sulfate is presented that couples the experimental HS recovery rate constants with published membrane trafficking constants to provide a phenotype-specific picture of HS trafficking on the endothelial surface.

\section{ACKNOWLEDGMENTS}

This research was supported by the National Institutes of Health Grant HL090856-01 from the Heart, Lung, and Blood Institute and through the SingaporeMIT Alliance, Computational and Systems Biology Program.

\section{DISCLOSURES}

No conflicts of interest, financial or otherwise, are declared by the author(s). Dr. Giantsos-Adams' current affiliation is with the Department of Pharmacology, University of Illinois Chicago, 835 South Wolcott Avenue, Chicago, IL.

\section{OPEN ACCESS}

This article is distributed under the terms of the Creative Commons Attribution License which permits any use, distribution, and reproduction in any medium, provided the original author(s) and the source are credited.

\section{REFERENCES}

\footnotetext{
${ }^{1}$ Adamson, R. H., and G. Clough. Plasma proteins modify the endothelial cell glycocalyx of frog mesenteric microvessels. J. Physiol. 445:473-486, 1992.

${ }^{2}$ Ainslie, K. M., J. S. Garanich, R. O. Dull, and J. M. Tarbell. Vascular smooth muscle cell glycocalyx influences shear stress-mediated contractile response. J. Appl. Physiol. 98(1):242-249, 2005.

${ }^{3}$ Arisaka, T., M. Mitsumata, M. Kawasumi, T. Tohjima, S. Hirose, and Y. Yoshida. Effects of shear stress on glycosaminoglycan synthesis in vascular endothelial cells. Ann. N. Y. Acad. Sci. 748:543-554, 1995.

${ }^{4}$ Bai, X., K. J. Bame, H. Habuchi, K. Kimata, and J. D. Esko. Turnover of heparan sulfate depends on 2-Osulfation of uronic acids. J. Biol. Chem. 272(37):2317223179, 1997.

${ }^{5}$ Baker, A. B., Y. S. Chatzizisis, R. Beigel, M. Jonas, B. V. Stone, A. U. Coskun, C. Maynard, C. Rogers, K. C. Koskinas, C. L. Feldman, P. H. Stone, and E. R. Edelman. Regulation of heparanase expression in coronary artery
}

disease in diabetic, hyperlipidemic swine. Atherosclerosis 213(2):436-442, 2010.

${ }^{6}$ Ballinger, M. L., J. Nigro, K. V. Frontanilla, A. M. Dart, and P. J. Little. Regulation of glycosaminoglycan structure and atherogenesis. Cell. Mol. Life Sci. 61(11):1296-1306, 2004.

${ }^{7}$ Barkefors, I., C. K. Aidun, and E. M. Ulrika Egertsdotter. Effect of fluid shear stress on endocytosis of heparan sulfate and low-density lipoproteins. J. Biomed. Biotechnol. 2007:65136, 2007.

${ }^{8}$ Carter, N. M., S. Ali, and J. A. Kirby. Endothelial inflammation: the role of differential expression of $\mathrm{N}$ deacetylase/N-sulphotransferase enzymes in alteration of the immunological properties of heparan sulphate. J. Cell Sci. 116(17):3591-3600, 2003.

${ }^{9}$ Chappell, D., M. Jacob, M. Rehm, M. Stoeckelhuber, U. Welsch, P. Conzen, and B. F. Becker. Heparinase selectively sheds heparan sulphate from the endothelial glycocalyx. Biol. Chem. 389(1):79-82, 2008.

${ }^{10}$ Dai, G., M. R. Kaazempur-Mofrad, S. Natarajan, Y. Zhang, S. Vaughn, B. R. Blackman, R. D. Kamm, G. Garcia-Cardena, and M. A. Gimbrone, Jr. Distinct endothelial phenotypes evoked by arterial waveforms derived from atherosclerosis-susceptible and -resistant regions of human vasculature. Proc. Natl. Acad. Sci. USA. 101(41): 14871-14876, 2004.

${ }^{11}$ Dull, R. O., I. Mecham, and S. McJames. Heparan sulfates mediate pressure-induced increase in lung endothelial hydraulic conductivity via nitric oxide/reactive oxygen species. Am. J. Physiol. Lung Cell Mol. Physiol. 292(6): L1452-L1458, 2007.

${ }^{12}$ Ebong, E. E., F. P. Macaluso, D. C. Spray, and J. M. Tarbell. Imaging the endothelial glycocalyx in vitro by rapid freezing/freeze substitution transmission electron microscopy. Arterioscler. Thromb. Vasc. Biol. 31(8):19081915, 2011.

${ }^{13}$ Esko, J. D., and U. Lindahl. Molecular diversity of heparan sulfate. J. Clin. Investig. 108(2):169-173, 2001.

${ }^{14}$ Ferro, V., L. Liu, K. D. Johnstone, N. Wimmer, T. Karoli, P. Handley, J. Rowley, K. Dredge, C. P. Li, E. Hammond, K. Davis, L. Sarimaa, J. Harenberg, and I. Bytheway. Discovery of PG545: a highly potent and simultaneous inhibitor of angiogenesis, tumor growth, and metastasis. J. Med. Chem. 55(8):3804-3813, 2012.

${ }^{15}$ Florian, J. A., J. R. Kosky, K. Ainslie, Z. Pang, R. O. Dull, and J. M. Tarbell. Heparan sulfate proteoglycan is a mechanosensor on endothelial cells. Circ. Res. 93(10):e136e142, 2003.

${ }^{16}$ Fuki, I. V., M. E. Meyer, and K. J. Williams. Transmembrane and cytoplasmic domains of syndecan mediate a multi-step endocytic pathway involving detergentinsoluble membrane rafts. Biochem. J. 351(Pt 3):607-612, 2000.

${ }^{17}$ Gao, L., and H. H. Lipowsky. Composition of the endothelial glycocalyx and its relation to its thickness and diffusion of small solutes. Microvasc. Res. 80(3):394-401, 2010.

${ }^{18}$ Gouverneur, M., J. A. Spaan, H. Pannekoek, R. D. Fontijn, and H. Vink. Fluid shear stress stimulates incorporation of hyaluronan into endothelial cell glycocalyx. Am. J. Physiol. Heart Circ. Physiol. 290(1):H458-H452, 2006.

${ }^{19}$ Gross, A. W., and H. F. Lodish. Cellular trafficking and degradation of erythropoietin and novel erythropoiesis 
stimulating protein (NESP). J. Biol. Chem. 281(4):2024 2032, 2006.

${ }^{20}$ Kennett, E. C., M. D. Rees, E. Malle, A. Hammer, J. M. Whitelock, and M. J. Davies. Peroxynitrite modifies the structure and function of the extracellular matrix proteoglycan perlecan by reaction with both the protein core and the heparan sulfate chains. Free Radic. Biol. Med. 49(2):282-293, 2010.

${ }^{21}$ Khan, A. G., A. Pickl-Herk, L. Gajdzik, T. C. Marlovits, R. Fuchs, and D. Blaas. Entry of a heparan sulphatebinding HRV8 variant strictly depends on dynamin but not on clathrin, caveolin, and flotillin. Virology 412(1):55-67, 2011.

${ }^{22}$ Koo, A., C. F. Dewey, Jr, and G. Garcia-Cardena. Hemodynamic shear stress characteristic of atherosclerosisresistant regions promotes glycocalyx formation in cultured endothelial cells. Am. J. Physiol. Cell Physiol. 304(2):C137C146, 2013.

${ }^{23}$ Lipowsky, H. H. Protease activity and the role of the endothelial glycocalyx in inflammation. Drug Discov. Today Dis. Models 8(1):57-62, 2011.

${ }^{24}$ Mulivor, A. W., and H. H. Lipowsky. Inflammation- and ischemia-induced shedding of venular glycocalyx. Am. J. Physiol. Heart Circ. Physiol. 286(5):H1672-H1680, 2004.

${ }^{25}$ Mulivor, A. W., and H. H. Lipowsky. Inhibition of glycan shedding and leukocyte-endothelial adhesion in postcapillary venules by suppression of matrixmetalloprotease activity with doxycycline. Microcirculation 16(8):657-666, 2009.

${ }^{26}$ Nikmanesh, M., Z. D. Shi, and J. M. Tarbell. Heparan sulfate proteoglycan mediates shear stress-induced endothelial gene expression in mouse embryonic stem cell-derived endothelial cells. Biotechnol. Bioeng. 109(2):583-594, 2012.

${ }^{27} \mathrm{O}^{\prime}$ Neill, M. J., J. Guo, C. Byrne, R. Darcy, and C.M. O' Driscoll. Mechanistic studies on the uptake and intracellular trafficking of novel cyclodextrin transfection complexes by intestinal epithelial cells. Int. J. Pharm. 413 (1-2):174-183, 2011.

${ }^{28}$ Pahakis, M. Y., J. R. Kosky, R. O. Dull, and J. M. Tarbell. The role of endothelial glycocalyx components in mechanotransduction of fluid shear stress. Biochem. Biophys. Res. Commun. 355(1):228-233, 2007.

${ }^{29}$ Parmar, K. M., H. B. Larman, G. Dai, Y. Zhang, E. T. Wang, S. N. Moorthy, J. R. Kratz, Z. Lin, M. K. Jain, M. A. Gimbrone, Jr, and G. Garcia-Cardena. Integration of flow-dependent endothelial phenotypes by Kruppel-like factor 2. J. Clin. Invest. 116(1):49-58, 2006.

${ }^{30}$ Payne, C. K., S. A. Jones, C. Chen, and X. Zhuang. Internalization and trafficking of cell surface proteoglycans and proteoglycan-binding ligands. Traffic 8(4):389-401, 2007.

${ }^{31}$ Potter, D. R., J. Jiang, and E. R. Damiano. The recovery time course of the endothelial cell glycocalyx in vivo and its implications in vitro. Circ. Res. 104(11):1318-1325, 2009.

${ }^{32}$ Rao, G., H. G. Ding, W. Huang, D. Le, J. B. Maxhimer, A. Oosterhof, T. van Kuppevelt, H. Lum, E. J. Lewis, V. Reddy, R. A. Prinz, and X. Xu. Reactive oxygen species mediate high glucose-induced heparanase-1 production and heparan sulphate proteoglycan degradation in human and rat endothelial cells: a potential role in the pathogenesis of atherosclerosis. Diabetologia 54(6):1527-1538, 2011.
${ }^{33}$ Reitsma, S., M. G. Oude Egbrink, V. V. Heijnen, R. T. Megens, W. Engels, H. Vink, D. W. Slaaf, and M. A. van Zandvoort. Endothelial glycocalyx thickness and plateletvessel wall interactions during atherogenesis. Thromb. Haemost. 106(5):939-946, 2011.

${ }^{34}$ Remuzzi, A., C. F. Dewey, Jr, P. F. Davies, and M. A. Gimbrone, Jr. Orientation of endothelial cells in shear fields in vitro. Biorheology 21(4):617-630, 1984.

${ }^{35}$ Rudd, T. R., K. A. Uniewicz, A. Ori, S. E. Guimond, M. A. Skidmore, D. Gaudesi, R. Xu, J. E. Turnbull, M. Guerrini, G. Torri, G. Siligardi, M. C. Wilkinson, D. G. Fernig, and E. A. Yates. Comparable stabilisation, structural changes and activities can be induced in FGF by a variety of HS and non-GAG analogues: implications for sequence-activity relationships. Org. Biomol. Chem. 8(23):5390-5397, 2010.

${ }^{36}$ Sarrazin, S., W. C. Lamanna, and J. D. Esko. Heparan sulfate proteoglycans. Cold Spring Harb. Perspect. Biol. 3:1-33, 2011.

${ }^{37}$ Shafat, I., N. Ilan, S. Zoabi, I. Vlodavsky, and F. Nakhoul. Heparanase levels are elevated in the urine and plasma of type 2 diabetes patients and associate with blood glucose levels. PLoS ONE 6(2):e17312, 2011.

${ }^{38}$ Takeuchi, Y., K. Sakaguchi, M. Yanagishita, G. D. Aurbach, and V. C. Hascall. Extracellular calcium regulates distribution and transport of heparan sulfate proteoglycans in a rat parathyroid cell line. J. Biol. Chem. 265(23):13661-13668, 1990.

${ }^{39}$ van den Berg, B. M., J. A. Spaan, T. M. Rolf, and H. Vink. Atherogenic region and diet diminish glycocalyx dimension and increase intima-to-media ratios at murine carotid artery bifurcation. Am. J. Physiol. Heart Circ. Physiol. 290(2):H915-H920, 2006.

${ }^{40}$ Villarreal, G., Jr., Y. Zhang, H. B. Larman, J. GraciaSancho, A. Koo, and G. Garcia-Cardena. Defining the regulation of KLF4 expression and its downstream transcriptional targets in vascular endothelial cells. Biochem. Biophys. Res. Commun. 391(1):984-989, 2010.

${ }^{41}$ Vlodavsky, I., A. Eldor, A. Haimovitz-Friedman, Y. Matzner, R. Ishai-Michaeli, O. Lider, Y. Naparstek, I. R. Cohen, and Z. Fuks. Expression of heparanase by platelets and circulating cells of the immune system: possible involvement in diapedesis and extravasation. Invasion Metastasis 12(2):112-127, 1992.

${ }^{42}$ Vlodavsky, I., M. Elkin, O. Pappo, H. Aingorn, R. Atzmon, R. Ishai-Michaeli, A. Aviv, I. Pecker, and Y. Friedmann. Mammalian heparanase as mediator of tumor metastasis and angiogenesis. Isr. Med. Assoc. J. 2(Suppl):37-45, 2000.

${ }^{43}$ Yanagishita, M., and V. C. Hascall. Metabolism of proteoglycans in rat ovarian granulosa cell culture. Multiple intracellular degradative pathways and the effect of chloroquine. J. Biol. Chem. 259(16):10270-10283, 1984.

${ }^{44}$ Yao, Y., A. Rabodzey, and C. F. Dewey, Jr. Glycocalyx modulates the motility and proliferative response of vascular endothelium to fluid shear stress. Am. J. Physiol. Heart Circ. Physiol. 293(2):H1023-H1030, 2007.

${ }^{45}$ Zimmermann, P., Z. Zhang, G. Degeest, E. Mortier, I. Leenaerts, C. Coomans, J. Schulz, F. N'Kuli, P. J. Courtoy, and G. David. Syndecan recycling [corrected] is controlled by syntenin-PIP2 interaction and Arf6. Dev. Cell 9(3):377-388, 2005. 